\title{
Alfabetização como uma construção dialógica no conhecimento e aprendizado da leitura e escrita
}

\section{Literacy as a dialogic construction of knowledge and of reading and writing learning}

\author{
Soraia Souza Cardoso é Mestranda do Programa Formação \\ de Formadores da PUC-SP e professora da rede Municipal de \\ São Paulo. Foi Coordenadora Pedagógica na rede Estadual e \\ Orientadora de Estudos do Pacto Nacional pela Alfabetização na \\ Idade Certa (PNAIC).
}

Contato: soraiacardoso3@gmail.com

\section{Resumo}

0 presente artigo objetiva a reflexão sobre os desafios - e a superação destes - que se apresentam ao processo de ensino-aprendizagem, no que se refere à alfabetização, evidenciados em uma situação prática observada em uma sala de aula. 0 aprofundamento sobre o assunto desvelou a importância da teoria sócio-histórica, notadamente pautada no pensamento de Piaget, Vygotsky e Freire, para entender como se dá a apropriação do conhecimento, reconhecendo a relevância do contexto em que a criança está inserida, bem como reconhecê-la como sujeito da aprendizagem, na qual sua história é considerada. A figura do professor é essencial no sentido de planejar, agir e refletir sobre sua ação, na intenção de propor intervenções pontuais a fim de promover esse aprendizado de maneira contextualizada.

Palavras-chave: educação, alfabetização, letramento.

\section{Abstract}

This article aims to reflect on the challenges - and on how to overcome them - that are present in the teachinglearning process, regarding to literacy, evidenced in a practical situation observed in a classroom. The deepening on the subject unveiled the importance of the socio- 
historical theory, notably guided by the thinking of Piaget, Vygotsky and Freire, in understanding how the acquisition of knowledge happens, recognizing the relevance of the context in which the child is inserted, as well as recognizing the child as a subject of learning, in which her history is considered. The figure of the teacher is essential in order to plan, act and reflect on the child's action, in order to make occasional interventions to promote the learning in a contextualized manner.

Keywords: education, literacy

Paulo Freire afirmou que a "leitura do mundo precede a leitura da palavra" (FREIRE, 2009, p.11) e, para pensar em alfabetização, é necessário conhecermos a criança, nosso sujeito da aprendizagem, qual o seu contexto de vida, que experiência traz consigo e, a partir daí, encaminhar o processo de alfabetização numa perspectiva significativa.

Freire afirma também que no cerne da pedagogia do saber encontra-se a ideia de que nomear o mundo torna-se um modelo para transformar o mundo. A educação não substitui a ação política, mas lhe é indispensável devido ao papel que desempenha no desenvolvimento da consciência crítica. Isso, por sua vez, depende do poder transformador da linguagem. Assim, o decodificar, que é o aprendizado entre letras e sons, caminha lado a lado com a interpretação. Então, podemos concluir que o significado está presente desde o início, à medida que os alunos "problematizam o existencial" (FREIRE, 1990, p. 17).

0 processo de alfabetização deve ocorrer de forma significativa, com atividades contextualizadas, e os projetos são ótimos aliados nessa intenção, que deve ser carregada de sentido à criança, que, se motivada, desafiada e acompanhada de intervenções pontuais, se desenvolverá plenamente.

0 professor alfabetizador precisa trabalhar com base na pedagogia de projetos e, nessa perspectiva, ensinar requer escolhas didáticas e de instrumentos conceituais para tornar possível que as crianças vivam situações imediatas de aprendizagem e que, por meio dessas, sejam realizadas avaliações contínuas para o replanejamento da ação educativa. Na pedagogía de projetos não se pode planejar sem antes fazer a "recognição por parte do professor", que Paulo Freire define como o reconhecimento daquilo que a criança sabe a respeito desse conhecimento, respeitando-se a pluralidade de vozes, a variedade 
de discursos e, naturalmente, linguagens diferentes. Toda atividade humana é intencional e tem, por isso, uma direção. Um professor que não se empenhe em permitir que essa direção seja aprendida e que não entre em ação dialógica para examiná-la estará se recusando à "tarefa pedagógica, política e epistemológica de assumir o papel de sujeito dessa prática diretiva" (FREIRE 1990, p. 29)

Ao eleger o que e como ensinar, é fundamental levar em consideração esses fatos, não mais para justificar fracassos, mas para criar as condições necessárias para possibilitar a conquista e a consolidação da aprendizagem da leitura e da escrita e, a partir daí, encaminhar o processo de alfabetização numa perspectiva significativa.

Porém, percebemos a heterogeneidade de saberes, as diferenças individuais e o tempo de cada criança, fatores que nem sempre permitem que todas se alfabetizem no mesmo ano/ série. Isso não quer dizer que ela não tenha se desenvolvido, pois na alfabetização, assim como na Educação Infantil, os registros são muito importantes, pois retratam o trajeto das experiências e aprendizagens, sejam coletivas ou individuais, na expressão oral, na relação com os colegas e com o objeto de aprendizag'em, no raciocínio lógico, na estrutura simbólica, no desenho, na escrita, na leitura, na expressão corporal etc. Esses registros são importantes ferramentas para avaliação, reflexão e nova ação, seja para os professores, coordenadores pedagógicos/equipe gestora, seja para os pais e as crianças. Por meio deles é possível perceber o seu desempenho na tarefa de ensinar e aprender, já que a educação nessa perspectiva é dialógica, porque entende que o pressuposto do diálogo é sair de si mesmo e abrir-se ao outro, pois, segundo Freire (1987, p. 81 e 84), "não há ignorantes absolutos, nem sábios absolutos: há homens que, em comunhão, buscam saber mais [...] A educação autêntica não se faz de A para B ou de A sobre B, mas de A com B".

Enquanto professora coordenadora na rede estadual de São Paulo, acompanhei a experiência de um professor que lecionava em uma turma de $5^{\circ}$ ano, com alunos repetentes, indisciplinados e muito desmotivados, mas que foram mudando seu comportamento e mostraram interesse nas atividades propostas no decorrer do ano letivo, pelo fato de o docente buscar uma aproximação ao universo dos educandos, tentando descobrir algo significativo sobre eles, para assim iniciar e/ou continuar o processo de alfabetização.

Nessa perspectiva, esse professor aproximou-se das crianças e, pouco a pouco, foi ganhando confiança delas. Descobriu as 
condições precárias em que algumas famílias viviam, a ausência de atividades de cultura, lazer e serviços básicos. Como exemplo, pode-se citar o caso de um aluno que morava em um apartamento da Companhia de Desenvolvimento Habitacional e Urbano (CDHU) próximo da escola, cujo pai era muito autoritário, a mãe deficiente visual e o irmão conformado com a situação. Ele rejeitava sua realidade, não demonstrava muito afeto pelo pai e pelo irmão e sentia vergonha da cegueira da mãe; como fuga, talvez, foi se apegando ao prazer da convivência com sua cachorrinha. Foi a partir dessa situação que o professor iniciou o processo de alfabetização com essa criança, sendo que a primeira palavra que ela foi desafiada a escrever e a ler foi o nome da sua cachorrinha: "LELINHA". Houve muita dificuldade, mas o interesse foi aos poucos derrubando os obstáculos. Depois vieram outras palavras sugeridas pela criança, que tinha um interesse pelo universo animal e, partindo dele, o professor fazia as intervenções para a construção da leitura e escrita.

Interessei-me pelo progresso na escrita dessa criança, e da turma, que também foi envolvida nesse processo, e passei a fazer os registros por meio de vídeos, fotos e atividades escritas, focando na criança interagindo com seu professor. Essa atitude pedagógica do professor de observar o contexto, descobrir o que era significativo para essa criança tão desinteressada pelos assuntos escolares, tornou possível que seu aluno fosse alfabetizado aos 10 anos, deixando ele de ser mais um caso de analfabetismo. Então, pensando nessa prática bem-sucedida, essa experiência foi socializada em momentos de formação coletiva na escola, na qual o professor pôde, junto com seus pares, refletir sobre essa experiência que vai ao encontro das ideias de Freire, para quem:

...seria impossível engajar-me num trabalho de memorização mecânica dos ba-be-bi-bo-bu, dos la-le-li-lo-lu. Daí que também não pudesse reduzir a alfabetização ao ensino puro da palavra, das sílabas, das letras. Ensino em cujo processo o alfabetizador fosse "enchendo" com suas palavras as cabeças supostamente "vazias" dos alfabetizandos. Pelo contrário, enquanto ato de conhecimento e ato criador, o processo da alfabetização tem, no alfabetizando, o seu sujeito. 0 fato de ele necessitar da ajuda do educador, como ocorre em qualquer relação pedagógica, não significa dever a ajuda do educador anular sua criatividade e a sua responsabilidade na criação de sua linguagem escrita e na leitura dessa linguagem. Na verdade, tanto o alfabetizador quanto o alfabetizando, ao pegarem, por exemplo, um objeto, percebem o objeto sentido e são capazes de expressar verbalmente o objeto sentido e percebido. Como eu, o analfabeto é capaz de sentir a caneta, de perceber a caneta e de dizer caneta. Eu, porém, sou 


\begin{abstract}
capaz de não apenas sentir a caneta, de perceber a caneta, de dizer caneta, mas também de escrever caneta e, consequentemente, de ler caneta. A alfabetização é a criação ou a montagem da expressão escrita da expressão oral. Essa montagem não pode ser feita pelo educador para ou sobre o alfabetizando... (FREIRE, 2009, p. 19).
\end{abstract}

Esse trabalho foi realizado a partir de projetos nos quais propiciavam-se atividades e estratégias para que as crianças pudessem ir construindo sua autonomia. A primeira proposta foi a escrita do "Diário de Bordo", pois dessa forma o professor conheceria melhor seus alunos. Nesse caderno destinado às anotações pessoais, as crianças relatavam diariamente como havia sido o dia escolar, os aspectos positivos e negativos, enfim, seus sentimentos mais íntimos. Porém, alguns alunos, prioritariamente esse citado, apresentavam muita dificuldade para realizar o registro, mas eram motivados a escrever, mesmo que ainda não soubessem de forma convencional.

Nessa concepção de alfabetização, o professor trabalhava com sua turma, priorizando o pensar certo, deixando para as crianças a decisão na resolução de alguns conflitos, fazendo com que entendessem sempre o significado e o significante de cada situação. Assim, a leitura do mundo precedia a leitura da palavra e a leitura desta dava continuidade à leitura anterior, fazendo com que percebessem que escrever e reescrever é sempre transformar o mundo, por meio de uma prática consciente.

Após esse trabalho, iniciou-se o projeto "Horta", que, além de envolver conteúdos de Ciências, trabalhou conceitos de cidadania, respeito à natureza, solidariedade, trabalho em equipe, entre outros. Havia um canteiro na escola onde o mato tomava conta e no qual há alguns anos havia uma horta. 0 professor primeiramente conversou com o grupo, despertando o interesse em reaver a horta da escola.

A turma abraçou a ideia e uma das alunas disse que os pais poderiam colaborar na limpeza do local, já que tinham experiência nisso. Então, o primeiro contato com o projeto foi a observação do local, as condições em que se apresentava, os cuidados que deveriam ter e a sequência de atividades que iriam realizar na construção da horta. Assim iniciou-se o trabalho.

0 professor sabia que esse projeto seria importante para a alfabetização dos seus alunos e investiu nele. Nesse primeiro contato, o professor levou todas as crianças à horta e, usando a expressão oral, todos puderam dar seu parecer sobre o local e as 
medidas que achavam prudentes para a realização da horta. E foi nessa atividade que percebeu o interesse e participação dos seus alunos, mas, em especial, a daquele que estamos citando, pois ele participou ativamente ressaltando a importância de retirar o mato, mas com cuidado para não extrair um pé de hortelã que havia no local. Após a conversa, as crianças fizeram um relatório de observação. É claro que as observações dessa criança foram acatadas pela turma de forma positiva e ele, se sentindo importante no grupo, não pôde fazer seu registro escrito, pois ainda não conseguia fazê-lo alfabeticamente, mas desenhou e tentou escrever algumas palavras que remetessem ao tema explorado.

Pensando nos ensinamentos de Paulo Freire, o professor sabia que esse movimento dinâmico é um dos aspectos centrais da alfabetização. Por isso utilizou as palavras do universo vocabular de sua turma e, em especial, daquele menino. Ali estavam expressos a linguagem real, os anseios, as inquietações e os sonhos carregados de significação de uma experiência existencial. Nesse ambiente, pouco a pouco esse menino avançava em sua leitura e escrita, sempre contando com a intervenção pontual do professor, que o desafiava com um conjunto de situações codificadas, de cuja leitura resultava a percepção crítica do que é cultura, pela compreensão da prática

0 importante é o respeito aos níveis de compreensão de cada aluno, pois cada um tem uma realidade própria. Na turma, vários alunos se destacavam por terem facilidade de compreensão e também por assumirem um papel crítico diante de um fato. E esse relacionamento social foi muito positivo para que esses alunos fossem, pouco a pouco, superando suas dificuldades e, dentro de suas limitações, avançaram significativamente na compreensão da leitura e escrita, pois a troca de saberes enriqueceu a turma e, no tema horta, o menino que até então era desinteressado e indisciplinado ensinou muito a seus colegas.

Paulo Freire, em seu livro A importância do ato de ler, escreve sabiamente que: 
E é exatamente o que acontecia nessa turma do $5^{\circ}$ ano. A cada desafio as crianças superavam as expectativas, sabendo se posicionar de forma crítica e se percebendo como parte do contexto. Lembro-me de acompanhar a turma quando foram assistir a um vídeo chamado "História do Brasil", apresentado pelo historiador Boris Fausto, no qual ele narrava a história da colonização do Brasil. Fiquei surpresa ao perceber o quanto essas crianças sabiam sobre o assunto. 0 professor pausava o vídeo, para que elas pudessem refletir e discutir sobre o exposto. Era fascinante vê-las pensando e relacionando, por exemplo, o porquê de falarmos português, o porquê de comermos alguns alimentos, o porquê do predomínio do catolicismo, entre outras questões. 0 professor mediava a conversa e intervinha quando necessário, mas era comum uma criança corrigir ou acrescer a fala de outra. Essa participação, no início, era irrefletida. Diziam qualquer coisa só para responder a alguma situação, mas o professor os instigava com novas perguntas, como, por exemplo: "Essa é a resposta mais provável? Poderia ter outra solução?". Então, começaram a participar mais conscientemente. Ao falarem, pensavam já nas outras possíveis perguntas à sua resposta, tentando sempre descobrir a razão de ser dos fatos.

0 professor reconhecia o que seus educandos sabiam e respeitava esse conhecimento, elaborando avaliações a partir do planejamento, sem perder o foco de seu objetivo geral. Assim, dava condições para que a turma toda tivesse acesso aos conteúdos, mas os objetivos eram diferentes com os alunos que ainda não tinham compreendido o sistema de leitura e escrita. A expressão oral destes melhorou muito e os registros no "Diário de Bordo" avançaram; até que, um dia, aquele aluno conseguiu escrever e ler seu primeiro relatório: os colegas e o professor o elogiaram e ele, se sentindo seguro, pediu ao professor para deixá-lo descer até a Coordenação, para me mostrar sua última realização. Ao chegar, estava um pouco tímido e contou que tinha trazido um texto escrito por ele para eu ler, e eu, no entusiasmo, pedi para que ele lesse. A resposta foi imediata: "Você não sabe ler?"

Ele queria que eu lesse e, assim, tive um pouco de dificuldade para entender a letra, mas não o demonstrei, pois ele, na impaciência, me corrigia a cada palavra. Parabenizei-o e disse que aquele seria o primeiro dos muitos que ele escreveria a partir daquele momento. É claro que o texto ainda era precário, com muitos erros ortográficos, mas ele estava se comunicando por meio da escrita. Isso após frequentar mais de três anos a mesma escola. Essa experiência reforça meu entendimento de como o 
fator emocional é fundamental na construção do conhecimento. 0 aluno teve sua autoestima trabalhada, assumindo o compromisso com o professor e com o grupo, por se sentir parte dele, pois foi aceito e respeitado dentro de suas limitações.

Para Freire (1990, p. 6), a alfabetização é um veículo para estudar de que modo definições culturais de gênero, raça, classe e subjetividade se constituem como construtores tanto históricos quanto sociais. Nessa perspectiva, o trabalho ia evoluindo a partir dos significados produtivos que os alunos, com todas as suas diferenças culturais e sociais, traziam para a sala de aula, como parte da produção de conhecimento e da construção da identidade pessoal e social.

0 acesso a diversos materiais e a textos variados possibilitou validar e investigar a produção de leituras diferenciais. Assim, as crianças eram estimuladas a examinar suas próprias posições teóricas e práticas, criando condições para identificação e problematização das maneiras contraditórias e múltiplas de ver o mundo. Em uma das aulas, o professor dividiu a sala como se fosse um tribunal. Escolheu um educando para ser o juiz, outro para advogado de defesa, outro para réu etc. Deu um texto para eles estudarem em casa e, no outro dia, o tribunal estava montado. Foi fantástico como cada criança encarnou seu papel e criou mecanismos para defender, argumentar, julgar, ou seja, ali estava a evidência de que os alunos haviam incorporado muitos conteúdos, assumiram o papel de sujeitos cognoscentes e viveram a experiência desses sujeitos. Dessa forma, percebi o quanto o professor desafiava seus alunos a compreender que, como sujeitos cognoscentes, a relação que se tem com objetos cognoscíveis não se pode reduzir apenas aos objetos. Foi preciso atingir um nível de compreensão da totalidade complexa de relações entre os objetos. Ou seja, era preciso desafiá-los a tratar criticamente o "varal de informações" com que estavam trabalhando (FREIRE, 1990, p. 79).

Outro momento importante foi quando, trabalhando a história de São Paulo, após várias leituras e reflexões, coletivamente as crianças e o professor escreveram a música SP Piratininga. Em um ritmo hip hop, concederam a visão crítica do conceito trabalhado no livro didático. Assim, para que a ideia de alfabetização ganhe significado, deve ser situada dentro de uma teoria de produção cultural e encarada como parte integrante do modo pelo qual as pessoas produzem, transformam e reproduzem significado. A alfabetização deve ser vista como um meio que compõe e afirma os momentos históricos e existenciais da experiência vivida que produzem uma cultura (FREIRE, 1990, p. 90). 
A alfabetização dentro de uma concepção de letramento deve ocorrer logo nos primeiros anos e, quando isso não ocorre, dificulta e desmotiva a criança a progredir. Pensemos em uma criança no $4^{\circ}$ ou $5^{\circ}$ ano do Ensino Fundamental, solicitada a expressar sua opinião sobre uma notícia e escrever uma carta de leitor, por exemplo, sem ao menos conseguir ler ou escrever alfabeticamente. Isso é fato, pois, mesmo frequentando a recuperação paralela e a contínua-intensiva, muitas crianças chegam ao $5^{\circ}$ ano sem ler e escrever, como o exemplo citado acima. Descrevi a experiência de uma turma com dificuldades na leitura e escrita, mas focando apenas a história de uma criança especificamente, para que percebamos o quanto se faz importante problematizar constantemente as vivências empíricas das crianças, para que escrevam e leiam praticando a escrita e a leitura, desafiadas em atividades práticas na realidade concreta e significativa delas. $\mathrm{E}$ conhecer todos os alunos para planejar melhores intervenções é atividade extremamente profissional que o docente desenvolve ao longo da sua carreira, conhecendo a subjetividade dos seus alunos e criando estratégias para atingi-los e desafiá-los a superarem suas dificuldades.

A Resolução SE 53 de 02/10/14 autoriza e regulamenta a reprovação ao final de cada ciclo. Ela pode ocorrer no $3^{\circ}$ ano, que é o encerramento do ciclo de alfabetização, e no $6^{\circ}$ ano, findando o ciclo interdisciplinar, deixando de ocorrer somente no $5^{\circ}$ ano do Ensino Fundamental, pois é necessário entender que a alfabetização é um processo e que pode ser concluído até os 8 anos de idade. Não é possível iniciar um novo ciclo sem ter encerrado o outro com as habilidades e competências necessárias à continuidade do próximo; porém, o desafio é garantir que essa retenção garanta a recuperação de ciclo e que seja realizada com êxito, já que a aprendizagem é continuada, mas as lacunas de tudo que não foi aprendido dentro das expectativas de aprendizagem de cada ano escolar refletirão na deficiência dos anos posteriores.

Norteando-se pelo pensamento de Paulo Freire, é imprescindível que os professores se atentem aos seus alunos no sentido de que percebam que, antes de essas crianças fazerem a leitura da palavra, elas leem o mundo por meio de gestos, olhares e expressões que criam sentido ao mundo que as rodeia, e é nesse contato estabelecido com o mundo e com o outro que criam símbolos e constroem significados que não podem ser desprezados por um professor atento. É nessa interação social que pode estar a abertura para a alfabetização e letramento daqueles alunos que apresentaram dificuldades na compreensão do sistema de escrita. 
Lembremos que nesse sentido, antes de ler a palavra, a criança já vivenciou diversas leituras do mundo em diferentes linguagens e contextos, e essas experiências devem ser consideradas e valorizadas, pois interferem na leitura da palavra. No caso exemplificado, não bastava dizer à criança que "0 cachorro baba e bebe água". Esse cachorro tem nome e um significado para a criança, que pode dizer ao professor o que quer escrever sobre ele.

Cada estado da Federação tem autonomia para regulamentar seu sistema de educação, mas o Poder Federal, por meio do Pacto Nacional pela Alfabetização da Idade Certa (PNAIC), preocupado com a situação nacional da Educação, se mobilizou e idealizou que a alfabetização deve ser garantida a todas as crianças até os 8 anos de idade. Ou seja, até o $3^{\circ}$ ano, todas crianças devem ler e escrever com autonomia. As que não alcançarem esse objetivo deverão ser retidas, não como punição, mas como direito garantido de terem um ano a mais como oportunidade de aprender o que não conseguiram, para assim prosseguir nos anos posteriores de ensino básico.

Pensar em alfabetização no $3^{\circ}$ ano para escolas da rede privada, onde ela acontece muitas vezes antes do $1^{\circ}$ ano, parece surpreendente, mas é fato na rede pública do nosso país, assunto que nos faz debruçar sobre quem são esses educandos e professores da rede. Quais são seus saberes e o que ainda necessitam aprender?

No livro Pedagogia da autonomia, Paulo Freire (1996) explica que ensinar exige rigorosidade metódica, pesquisa, respeito aos saberes dos educandos, criticidade, ética e estética, corporificação das palavras pelo exemplo, risco, aceitação do novo e rejeição a qualquer forma de discriminação, reflexão crítica sobre a prática e o reconhecimento e a assunção da identidade cultural. Tais exigências são fundamentais à prática docente sim, mas também é importante que o professor esteja ciente de que está em formação permanentemente. Pois o momento fundamental é o da reflexão crítica sobre a prática. É pensando criticamente a prática de hoje ou de ontem que se pode melhorar a próxima prática. 0 próprio discurso teórico, necessário à reflexão crítica, tem de ser de tal modo concreto que quase se confunda com a prática. Quanto melhor faça essa operação, tanto mais inteligência ganha da prática em análise e maior comunicabilidade exercem em torno da superação da ingenuidade pela rigorosidade (FREIRE, 1996, p. 39).

Os coordenadores pedagógicos na rede estadual de São Paulo recebem formação para subsidiar o trabalho coletivo na formação 
dos professores, e esse programa, chamado Ler e Escrever, é supervisionado por Telma Weisz, doutora em Psicologia pela Universidade de São Paulo, que foi orientada por Emília Ferreiro e é uma das criadoras do Programa de Formação de Professores Alfabetizadores (PROFA), lançado em 2001 pelo Ministério da Educação.

Referência em alfabetização, Telma Weisz acredita que formar leitores e gente capaz de escrever é uma tarefa de todos da escola, coordenadores, gestores e professores de todas as séries e disciplina, e que a leitura e escrita são o conteúdo central da escola e têm a função de incorporar a criança à cultura do grupo em que vive.

A aquisição da escrita é uma aprendizagem conceitual, pois, se a língua escrita é concebida como a compreensão de um sistema de representação em que a grafia das palavras e seu significado estão associados, a preocupação deve estar na perspectiva de a considerarmos como uma apropriação desse novo objeto de conhecimento levando em conta os elementos que compõem o sistema de escrita e as regras que o produzem (DURAN, 2009, p. 42).

Discípula de Piaget, Emilia Ferreiro acredita que se o objeto língua, como objeto conceitual, não está dado (apesar do conhecimento inconsciente do falante), tampouco o objeto escrita, como objeto conceitual, está dado pela mera existência de marcas, já que é preciso compreender as regras de composição das marcas, entrar nas entranhas do sistema para poder operar com ele. No processo de aquisição da escrita essas marcas redefinem-se continuamente, até corresponder àquelas que o sistema de representação define (e que seria ingênuo considerar como "naturais", em qualquer dos sentidos do termo). Contudo, o sistema de representação não é neutro. É um sistema que representa (objetivamente), mas que, por sua vez, gera novas representações (subjetivas). Por isso, os alfabetizados (não linguistas) estão condenados a supor que falam como escrevem, porque a escrita gera uma falsa consciência da fala. A representação escrita reverte sobre a consciência oral. A realidade psicológica da língua é sua representação escrita (FERREIRO, 2003, p. 154).

Vygotsky (1994) se preocupou em elaborar uma teoria sociopsicológica da relação pensamento e palavra como processo dinâmico, e a compreensão da linguagem como preenchendo funções psicológicas superiores e na construção da subjetividade. Seu interesse era desvendar implicações concretas e cotidianas 
da linguagem sobre a vida do homem e sobre a evolução da sociedade.

De acordo com Vygotsky (1994), no desenvolvimento cultural da criança toda função aparece duas vezes: primeiro em nível social e, mais tarde, em nível individual. Esse processo de internalização, quer dizer, de transformação de um processo interpessoal em um processo intrapessoal, implica a utilização de signos e supõe uma evolução complexa em que ocorre uma série de transformações qualitativas na consciência da criança. Dessa forma, estudar a constituição da consciência na infância não se resume em analisar o mundo interno em si mesmo, mas sim em resgatar o reflexo do mundo externo no mundo interno, ou seja, a interação da criança com a realidade (SOUZA, 1994, p. 125).

Assim, os significados das palavras são formações dinâmicas que se modificam e evoluem à medida que a criança se desenvolve e de acordo com as várias formas pelas quais o pensamento funciona. A observação do desenvolvimento da linguagem na criança revela a presença de um movimento independente em cada uma dessas esferas - fonética e semântica. Vygotsky observa que a criança começa a dominar a fala exterior, construindo-a da parte para o todo. Ou seja, para ele a criança, quando penetra na corrente da linguagem, começa utilizando sons que acabam por se traduzir em palavras, para, em seguida, articular palavras que irão formar frases numa complexidade cada vez mais ampla. Em relação ao significado, ocorre o inverso. A primeira palavra da criança tem a força de uma frase completa. Isso significa dizer que, semanticamente, a criança parte do todo indiferenciado ou de um complexo significativo e só mais tarde começa a dominar as unidades semânticas separadas.

À medida que o pensamento se torna mais diferenciado, não é mais possível expressar-se por meio de uma única palavra. 0 avanço da fala em direção às frases auxilia o pensamento a progredir de um todo homogêneo para partes mais bem definidas. Assim, a capacidade que tem a criança de se comunicar pela linguagem relaciona-se diretamente com a diferenciação dos significados das palavras na sua fala e na sua consciência.

A teoria de Piaget (2007) contempla uma universalidade na qual podemos situar o desenvolvimento da inteligência. Os três períodos básicos que cobrem uma linha evolutiva da inteligência demonstram o que é potencialmente possível para todos os seres humanos. 0 conhecimento não pode ser uma cópia, visto que é sempre uma relação entre objeto e sujeito. 
Os críticos de Piaget costumam dizer que ele deu importância excessiva aos processos individuais e internos de aquisição do aprendizado. Os que afirmam isso, em geral contrapõem a obra piagetiana à do pensador bielorrusso Lev Vygotsky (1896-1934). Para ele, como para Piaget, o aprendizado se dá por interação entre estruturas internas e contextos externos. A diferença é que, segundo Vygotsky, esse aprendizado depende fundamentalmente da influência ativa do meio social, que Piaget tendia a considerar apenas uma "interferência" na construção do conhecimento. Mas creio que Piaget queria abordar o conhecimento do ponto de vista de qualquer criança.

Dessa forma, conhecendo o processo de como as crianças se apropriam do saber e observando o contexto da sua turma, o professor tende a planejar suas intervenções com antecedência e, nesse sentido, manter-se atualizado com as novas pesquisas didáticas é essencial.

Partindo do pressuposto de que o professor alfabetizador tenha uma formação contínua e acredite nessa possibilidade construtivista de ensinar, é provável perceber que, em suas aulas, ele tenha se preocupado em:

- Realizar um diagnóstico sobre o que sabe cada um de seus alunos e o que é preciso ensinar.

- Organizar uma rotina na qual o planejamento contemple tarefas que favoreçam o confronto com textos, possibilitando a leitura diária dos vários gêneros textuais, e que, posteriormente, os alunos consigam redigir textos como listas ou cantigas memorizadas no início do processo de alfabetização.

- Organizar os alunos em grupos e duplas durante as atividades é fundamental para que eles troquem conhecimentos. Mas essa mistura deve ser feita com critérios. É preciso agrupar crianças que estejam em fases de alfabetização próximas. Quando você coloca uma que usa muitas letras para escrever cada palavra trabalhando com outra que usa uma letra para cada sílaba, a discussão pode ser produtiva. Como elas não sabem quem está com a razão, ambas terão de ouvir o colega, pensar a respeito, reelaborar seu pensamento e argumentar. Assim, as duas aprendem. Isso não ocorre, no entanto, se os dois estiverem em níveis muito diferentes. Nesse caso, é provável que o mais adiantado perca a paciência e queira fazer o serviço pelo outro. 
- Oferecer espaço para que os alunos reflitam sobre o sistema de escrita enquanto escrevem.

- Garantir que a leitura aconteça em vários momentos por meio da leitura realizada pelo professor, pelo aluno, compartilhada. Pois ouvir permite às crianças ampliar o repertório cultural, aumentar a familiaridade com a língua, desenvolver o comportamento leitor e iniciar o processo formal de alfabetização.

- Propor o texto oral com destino escrito, pois, ao desempenhar o papel de escriba e pedir aos alunos que criem oralmente um texto, o professor trabalha o comportamento escritor, as diferenças entre a linguagem oral e a escrita e a importância de sempre revisar o que é produzido, individual ou coletivamente.

- E, entre outras, oferecer atividades de escrita de palavras, de listas, de frases, textos e outras esferas da língua escrita, pois escrever leva o aluno a refletir a respeito do sistema alfabético, além de formular, testar e avançar nas próprias hipóteses.

Sabemos que muitos fatores interferem nessa questão e, entre eles, a insuficiente formação inicial dos professores alfabetizadores, que não dá conta de prepará-los para o ofício. Então, na tentativa de dar continuidade a essa formação, em muitas escolas ela acontece em in loco, dentro dos horários coletivos de estudo, e, quando efetiva, busca respostas às interrogações do nosso fazer pedagógico por intermédio das reflexões sobre nossa prática, para tomada de decisões que visem garantir a alfabetização. Como professora coordenadora, aconselho que seja priorizada no momento de formação coletiva na escola a troca de experiências, na qual os professores tenham voz para expor seus saberes e suas práticas, e que essas sejam estudadas à luz de teorias, como no exemplo do professor citado neste artigo, pois acredito que é nessa interação que caminhamos no sentido de uma formação mais ajustada a atender as necessidades do contexto escolar e das nossas crianças, já que elas escreverão o futuro desta nação. 


\section{REFERÊNCIAS}

FREIRE, Paulo. Pedagogia da autonomia: saberes necessários à prática educativa. Edição especial. São Paulo: Paz e Terra, 1996.

. A Importância do ato de ler: em três artigos que se completam. 50ª . ed. São Paulo: Cortez, 2009.

\& MACEDO, Donaldo. Alfabetização: leitura do mundo, leitura da palavra. $4^{a}$ ed. Rio de Janeiro: Paz e Terra, 1990.

SOUZA, Solange Jobim. Infância e Linguagem: Bakhtin, Vygotsky e Benjamin. 12ª ed. Campinas, SP: Papirus,1994.

ANDREOZZI, Maria Luiza. Piaget e a intervenção psicopedagógica. São Paulo: Olho D’Água, 2007.

DURAN, Marília Claret Geraes. Emilia Ferreiro: Uma concepção do desenvolvimento da escrita na criança. Petrópolis, RJ: Vozes, 2009.

FERREIRO, Emilia. Relações de (in)dependência entre a oralidade e escrita. Porto Alegre: Artmed, 2003.

NOVA ESCOLA, Revista. Edição Especial: Alfabetização e os grandes Pensadores. São Paulo. Mar/2009.

NOVA ESCOLA, Revista. Reunidas, duas das maiores especialistas em alfabetização. São Paulo, Edição 263, disponível em: http://goo.gl/4B2L64 - Acesso em:

24.jun.2016.

Recebido em: 9/03/2016

Revisto em: 25/04/2016

Aceito em: 24/04/2016

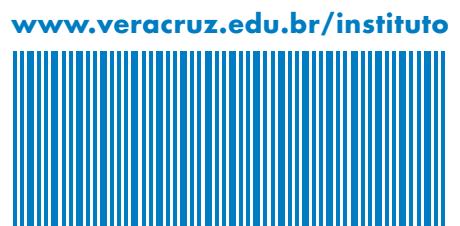

